\title{
Airway complications during gastrointestinal endoscopy using propofol in a rural hospital
}

\author{
Kelsey S. Flores ${ }^{1}$, Jungbin A. Choi, BA ${ }^{1}$, Kathleen N. Johnson, BS ${ }^{1}$, David P. Vaneenenaam Jr., \\ BS $^{1}$, Hannah M. Harris, BS ${ }^{2}$, Daniel J. Forest, MD ${ }^{3}$, Yvon F. Bryan, MD $^{4}$ \\ 1-Department of Anesthesiology, Wake Forest School of Medicine, Winston-Salem, North Carolina, USA. \\ 2-East Carolina University Brody School of Medicine, Greenville, North Carolina, USA. \\ 3-Department of Anesthesiology, Novant Health Forsyth Medical Center, Winston-Salem, North Carolina, USA. \\ 4-Department of Anesthesiology, Dartmouth-Hitchcock Medical Center, Lebanon, New Hampshire, USA.
}

Correspondence: Yvon F. Bryan, MD, Department of Anesthesiology, Dartmouth-Hitchcock Medical Center, 1 Medical Center Drive, Lebanon, NH 03766, USA; Telephone: 603-650-6719; E-mail: yvon.f.bryan@hitchcock.org; yvon.f.bryan@dartmouth.edu

\section{Abstract}

Background: Simple endoscopies such as esophagogastroduodenoscopy (EGD) and colonoscopies are common procedures that require the use of sedation or general anesthesia. The risk of airway complications for these procedures depends on the type of medications administered. Wide variation exists in reported rates of airway complications for endoscopic procedures. This retrospective study analyzed airway interventions and desaturations during simple endoscopy procedures performed by anesthesia-based teams (ABT) using propofol in a rural hospital.

Methodology: An IRB approved retrospective study was conducted at Wake Forest Baptist Lexington Medical Center (LMC). Patients over age 18 who underwent an EGD, colonoscopy, or both from July to December 2017 were included. Demographics, comorbidities, airway interventions, incidence of desaturation, the mean doses of propofol, and duration of procedures were recorded.

Results: Five hundred and thirteen patients underwent simple endoscopies (130 EGD, 320 colonoscopies, and 63 EGD/colonoscopy) at LMC. No patients required rescue intubation. One $(0.2 \%)$ patient required BMV, three $(0.6 \%)$ required a nasal airway, and three $(0.6 \%)$ required an oral airway. 44 patients desaturated; 11 (25\%) were severe and 33 (75\%) moderate.

Conclusion: We found that simple endoscopies performed by ABT had a low rate of airway interventions; however, the incidence of desaturation was higher than reported by other non-anesthesia-based teams and/or when clinicians used propofol for the endoscopies.

Key words: gastrointestinal endoscopy, endoscopic procedures, propofol, anesthesia, rural health, desaturations

Citation: Flores KS, Choi JA, Johnson KN, Vaneenenaam Jr. DP, Harris HM, Forest DJ, Bryan YF. Airway complications during gastrointestinal endoscopies using propofol in a rural hospital. Anaesth. pain intensive care 2020;24(4):420-425.

Received: 15 March 2020, Reviewed: 17 June 2020, Accepted: 27 June 2020

\section{Introduction}

There are a growing number of endoscopies performed in the world each year. Simple endoscopic procedures such as colonoscopies and esophagogastroduodenoscopies (EGDs) are recommended for aging adults. ${ }^{1}$ With the growing geriatric population in the United States, patients are more apt to require "out of operating room" anesthesia for endoscopic procedures. ${ }^{2}$

Variation exists on which clinicians administer sedation and/or general anesthesia for endoscopies. The clinicians vary from general practitioners, endoscopists, endoscopy-trained nurses, nurse 
anesthetists and anesthesiologists. ${ }^{3}$ In addition, variability occurs in the airway techniques used and medications administered. The doses and medications administered for endoscopies depends on the experience of the clinician and their skill with advanced airway management. Early et al reported that $16.9 \%$ of patients may undergo endoscopies without sedation, however the majority of patients require medications. ${ }^{4}$ The most commonly used sedatives and analgesics for endoscopy procedures are midazolam, propofol, and fentanyl, respectively. ${ }^{5}$ The deeper the sedation and the more comfortable the patient may be however, increases the risk of respiratory complications proportionately. ${ }^{5}$

Regardless of the technique used by the clinician, and/or medications administered, avoidance of airway complications is paramount. Previous studies have been performed in large academic medical centers or specialized GI practices, and not in rural hospitals. We sought to determine the incidence of airway interventions, complications, and desaturations; the mean doses of propofol used; and the duration of the procedures in simple endoscopies performed by anesthesia-based teams using propofol in a small rural hospital.

\section{Methodology}

An Institutional Review Board (IRB) approved, retrospective study with waiver of consent was performed at Lexington Medical Center (LMC) in Lexington, North Carolina, part of Wake Forest Baptist Health. This study included all patients over the age of 18 who underwent an EGD, colonoscopy, or both procedures together from July to December 2017. Prior to the study, in September 2015, the Department of Anesthesiology began an Anesthesiology-Based Team (ABT) program consisting of an anesthesiologist and a certified registered nurse anesthetist to administer a propofolbased anesthetic for all endoscopic procedures. Prior to this, nurses and physicians administered sedation for these procedures. In addition, a quality initiative (QI) was developed during this time to measure the variability in anesthetic practice along with the incidence of airway complications. The QI demonstrated a large variability in anesthetic techniques administered during endoscopic procedures at LMC. This observation led to the development of the retrospective study.

The following demographic data were recorded: age, height, weight, BMI, gender, and ASA status. Diagnosis, comorbidities, type of endoscopic procedure(s) performed (EGD, colonoscopy, or both EGD and colonoscopy), and any airway interventions and devices used as rescue for intubation and/or ventilation were also recorded. An airway intervention was defined as the need to intubate, and ventilation was defined as the need to bag mask ventilate and/or to insert a nasal or oral airway. A complication with oxygenation was defined as moderate if $\mathrm{SpO} 2$ was 80$89 \%$ and severe if $<79 \%$. Any aspiration events were also recorded. Medications administered were recorded including those administered preoperatively and intraoperatively. Propofol doses were reported as $\mathrm{mcg} / \mathrm{kg} / \mathrm{min}$ (calculated by addition of bolus and infusion doses). The times measured included the total time in the endoscopic suite, the time of the respective endoscopic procedure and the time during anesthesia. Data was supplemented by notes entered in the electronic medical chart by nurses, nurse anesthetists and anesthesiologists. Data was then compiled using RedCap data processing software.

\subsection{Statistical analysis}

The mean, standard deviation, and range were calculated for continuous variables. The number (n) and percentage (\%) were calculated for noncontinuous variables.

\section{Results}

\subsection{Demographics}

Five-hundred and thirteen patients underwent simple endoscopies at LMC: 130 EGD, 320 colonoscopies, and 63 EGD/colonoscopy. Demographics and diagnoses are reported in Tables 1 and 2, respectively.

\subsection{Airway management}

Intubation: Four $(0.7 \%)$ patients were intubated for their respective EGDs. All were planned intubations at the discretion of the anesthesiologists, and with two due to a food bolus and GI bleed, respectively.

Ventilation: One $(0.2 \%)$ patient required BMV, three $(0.6 \%)$ required a nasal airway, and three $(0.6 \%)$ required an oral airway. 
Oxygenation: Forty-four (8.6\%) patients desaturated. Incidence of desaturation was $7.7 \%, 8.8 \%$, and $9.5 \%$ for EGD, colonoscopy, and EGD/ colonoscopy, respectively (see Table 3 ).

Aspiration: No patients aspirated.

\subsection{Techniques}

The mean dose of propofol for all endoscopic procedures was $120.43 \pm 49.52 \mathrm{mcg} / \mathrm{kg} / \mathrm{min}$. The mean propofol dose was $115.6 \pm 58.8 \mathrm{mcg} / \mathrm{kg} / \mathrm{min}$ for EGD, $122.5 \pm 46.1 \mathrm{mcg} / \mathrm{kg} / \mathrm{min}$ for colonoscopy, and $119.9 \pm 45.7 \mathrm{mcg} / \mathrm{kg} / \mathrm{min}$ for EGD/colonoscopy (see Table 4).

The mean length of procedure time for all was $22.47 \pm$ $13.2 \mathrm{~min}$. The mean length of procedure was $9.8 \pm 6.3$ min for EGD, $25.0 \pm 11.2 \mathrm{~min}$ for colonoscopy, and $35.5 \pm 13.2 \mathrm{~min}$ for EGD/ colonoscopy (see Table 5).

Table 1: Demographic data

\begin{tabular}{|c|c|c|c|c|}
\hline Variable & $\begin{array}{l}\text { Total } \\
(n=513)\end{array}$ & $\begin{array}{c}\text { EGD } \\
(n=130)\end{array}$ & $\begin{array}{l}\text { Colonoscopy } \\
\qquad(n=320)\end{array}$ & $\begin{array}{l}\text { EGD/ Colonoscopy } \\
\qquad(n=63)\end{array}$ \\
\hline Age (y) & $\begin{array}{c}60.5 \pm 13.2 \\
(18-93)\end{array}$ & $\begin{array}{c}59.7 \pm 17.0 \\
(18-93)\end{array}$ & $\begin{array}{c}61.4 \pm 10.3 \\
(18-87)\end{array}$ & $\begin{array}{c}57.2 \pm 16.9 \\
(18-87)\end{array}$ \\
\hline Weight (kg) & $\begin{array}{c}85.9 \pm 22.2 \\
(41.3-215.5)\end{array}$ & $\begin{array}{c}82.8 \pm 22.2 \\
(48.1-147.9)\end{array}$ & $\begin{array}{l}87.3 \pm 21.5 \\
(45.4-215.5)\end{array}$ & $\begin{array}{c}85.4 \pm 24.7 \\
(41.3-166)\end{array}$ \\
\hline Height (m) & $\begin{array}{l}1.7 \pm 0.1 \\
(1.4-2.0)\end{array}$ & $\begin{array}{l}1.7 \pm 0.1 \\
(1.5-1.9)\end{array}$ & $\begin{array}{l}1.7 \pm 0.1 \\
(1.4-2.0)\end{array}$ & $\begin{array}{l}1.7 \pm 0.1 \\
(1.5-1.9)\end{array}$ \\
\hline BMI $\left(\mathrm{kg} / \mathrm{m}^{2}\right)$ & $\begin{array}{c}30.1 \pm 7.1 \\
(10.1-66.4)\end{array}$ & $\begin{array}{l}29.4 \pm 7.6 \\
(18-54.9)\end{array}$ & $\begin{array}{c}30.3 \pm 6.8 \\
(10.1-66.4)\end{array}$ & $\begin{array}{c}30.4 \pm 7.7 \\
(17.2-48.4)\end{array}$ \\
\hline \multicolumn{5}{|c|}{ Gender [n (\%)] } \\
\hline Male & $225(43.9)$ & $52(40)$ & $150(46.9)$ & $23(36.5)$ \\
\hline Female & $228(56.1)$ & $78(60)$ & $170(53.1)$ & $40(63.5)$ \\
\hline \multicolumn{5}{|c|}{ ASA Status [n (\%)] } \\
\hline I-II & $258(50.3)$ & $52(40)$ & $178(55.6)$ & $28(44.5)$ \\
\hline III-IV & $155(49.8)$ & $78(60)$ & $142(44.3)$ & $35(55.5)$ \\
\hline
\end{tabular}

Table 2-A: Diagnoses for EGD $(n=130)$

\begin{tabular}{lcc}
\multicolumn{1}{c}{ Diagnosis } & $\mathbf{n}$ & \% \\
\hline Pain & 19 & 14.6 \\
\hline Gastrointestinal Bleed & 16 & 12.3 \\
\hline Family History/ Screening & 14 & 10.8 \\
\hline Ulcer & 13 & 10 \\
\hline Dysphagia & 13 & 10 \\
\hline Esophageal Stricture & 12 & 9.2 \\
\hline Dyspepsia & 8 & 6.2 \\
\hline Nausea/ Vomiting & 7 & 5.4 \\
\hline GERD & 6 & 4.6 \\
\hline Gastritis & 5 & 3.8 \\
\hline Food Bolus & 4 & 3.1 \\
\hline Others (cirrhosis, esophagitis, & 22 & 16.9 \\
\hline hematuria, anemia, weight loss) & &
\end{tabular}

Table 2-B: Diagnoses for Colonoscopy $(n=320)$

\begin{tabular}{lcc}
\multicolumn{1}{c}{ Diagnosis } & $\mathbf{n}$ & $\%$ \\
\hline Screening & 94 & 29.4 \\
\hline History of Polyps & 65 & 20.3 \\
\hline Colorectal Cancer & 65 & 20.3 \\
\hline Blood in Stool & 21 & 6.6 \\
\hline Family History & 17 & 5.3 \\
\hline Hematochezia & 15 & 4.7 \\
\hline Gastrointestinal Bleed & 12 & 3.8 \\
\hline Anemia & 10 & 3.1 \\
\hline Abdominal Pain & 9 & 2.8 \\
\hline Weight Loss & 6 & 1.9 \\
\hline Constipation & 4 & 1.3 \\
\hline $\begin{array}{l}\text { Other (diverticulitis, colitis, } \\
\text { change in bowel habits, } \\
\text { irritable bowel syndrome) }\end{array}$ & 18 & 5.6 \\
\hline
\end{tabular}


Table 2-C: Diagnoses for EGD/ Colonoscopy $(n=63)$

\begin{tabular}{|c|c|c|}
\hline Diagnosis & $\mathbf{n}$ & $\%$ \\
\hline Pain & 19 & 30.2 \\
\hline Screening/ Family History & 14 & 22.2 \\
\hline GERD & 13 & 20.6 \\
\hline History of Polyps & 10 & 15.9 \\
\hline Anemia & 8 & 12.7 \\
\hline Nausea/ Vomiting & 8 & 12.7 \\
\hline Hematochezia & 6 & 9.5 \\
\hline Dysphagia & 6 & 9.5 \\
\hline Diarrhea & 5 & 7.9 \\
\hline Esophagitis & 4 & 6.3 \\
\hline Others* & 27 & 42.9 \\
\hline \multicolumn{3}{|c|}{$\begin{array}{l}\text { *Abnormal feces, dyspepsia, diverticulitis, } \\
\text { disorder of function of stomach, colorectal } \\
\text { cancer, weight loss, barrett's esophagus } \\
{ }^{*} \text { Some patients had more than one diagnosis }\end{array}$} \\
\hline
\end{tabular}

Table 3: Desaturations $(n=44)$

\begin{tabular}{l|c|c|c|c}
$\begin{array}{c}\text { SpO2 } \\
(\%)\end{array}$ & EGD & Colonoscopy & $\begin{array}{c}\text { EGD/ } \\
\text { Colonoscopy }\end{array}$ & Total \\
\hline $\begin{array}{l}\text { Severe } \\
(<79)\end{array}$ & $4(40)$ & $5(17.9)$ & $2(33.3)$ & $\begin{array}{c}11 \\
(25)\end{array}$ \\
\hline $\begin{array}{l}\text { Moderate } \\
(80-89)\end{array}$ & $6(60)$ & $23(82.1)$ & $4(66.7)$ & $\begin{array}{c}33 \\
(75)\end{array}$ \\
\hline Total & $\begin{array}{c}\mathbf{1 0} \\
\mathbf{( 2 2 . 7 )}\end{array}$ & $\mathbf{2 8 ( 6 3 . 6 )}$ & $\mathbf{6 ( 1 3 . 6 )}$ & $\begin{array}{c}\mathbf{4 4} \\
\mathbf{( 1 0 0 )}\end{array}$ \\
\hline
\end{tabular}

Table 4: Premedication and anesthetic agents used

\begin{tabular}{|c|c|c|c|c|}
\hline \multicolumn{2}{|c|}{ Drugs } & $\begin{array}{c}\text { EGD } \\
(n=130)\end{array}$ & $\begin{array}{l}\text { Colonoscopy } \\
(n=320)\end{array}$ & $\begin{array}{l}\text { EGD/ Colonoscopy } \\
(n=63)\end{array}$ \\
\hline \multirow{4}{*}{ Premedications } & Midazolam & $31(23.8)$ & $10(3.1)$ & $24(38.1)$ \\
\hline & Fentanyl & $7(5.4)$ & $0(0)$ & $1(1.6)$ \\
\hline & Glycopyrrolate & 69 (53.1) & $118(36.9)$ & $34(54)$ \\
\hline & Other* & $15(11.5)$ & $19(5.9)$ & $10(15.9)$ \\
\hline \multirow{3}{*}{$\begin{array}{l}\text { Intraoperative } \\
\text { Medications }\end{array}$} & Propofol $^{* *}$ & $82(63.1)$ & $308(96.3)$ & $33(52.4)$ \\
\hline & $\begin{array}{l}\text { Propofol and } \\
\text { Ketamine }^{\star *}\end{array}$ & 47 (36.2) & $12(3.75)$ & $30(47.6)$ \\
\hline & Ketamine & $1(0.8)$ & $0(0)$ & $0(0)$ \\
\hline
\end{tabular}

Table 5: Times (min)

\begin{tabular}{|c|c|c|c|c|}
\hline Time in & $\begin{array}{c}\text { EGD } \\
(n=130)\end{array}$ & $\begin{array}{l}\text { Colonoscopy } \\
(n=320)\end{array}$ & $\begin{array}{c}\text { EGD/ } \\
\text { Colonoscopy } \\
(n=63)\end{array}$ & $\begin{array}{c}\text { Total } \\
(n=513)\end{array}$ \\
\hline In-room & $\begin{array}{c}23.5 \pm 9.0 \\
(13-70)\end{array}$ & $\begin{array}{c}36.9 \pm 12.9 \\
(12-138)\end{array}$ & $\begin{array}{c}48.3 \pm 13.8 \\
(24-109)\end{array}$ & $\begin{array}{c}34.9 \pm 14.3 \\
(12-138)\end{array}$ \\
\hline Anesthesia & $\begin{array}{c}20.4 \pm 10.6(10- \\
102)\end{array}$ & $\begin{array}{c}33.3 \pm 12.2 \\
(12-131)\end{array}$ & $\begin{array}{c}43.9 \pm 13.5 \\
(22-109)\end{array}$ & $\begin{array}{c}31.3 \pm 14.0 \\
(10-131)\end{array}$ \\
\hline Procedure & $\begin{array}{c}9.8 \pm 6.3 \\
(3-44)\end{array}$ & $\begin{array}{c}25.0 \pm 11.2 \\
(6-100)\end{array}$ & $\begin{array}{c}35.5 \pm 13.2 \\
(15-85)\end{array}$ & $\begin{array}{c}22.5 \pm 13.2 \\
(3-100)\end{array}$ \\
\hline
\end{tabular}




\section{Discussion}

We found that all simple endoscopies were safely completed by anesthesia-based teams (ABT) using propofol in a rural hospital. None of the patients were intubated as rescue other than those whose initial airway plan was intubation for their respective EGD. However, we found our incidence of desaturations was higher than previously reported in other studies. Our findings demonstrate that propofol may be used safely by $\mathrm{ABT}$ for simple endoscopies in small rural hospitals.

Desaturation events during endoscopies in the literature range from as low as $0.0014 \%$ to $9 \% .^{6-10}$ However, no standardized definition of desaturation exists in regards to the duration, severity, and/or frequency of desaturation events. Goudra et al. found a $0.005 \%$ incidence, defined as desaturation events that were life-threatening and that required immediate intervention. $^{7}$ We did not have life-threatening hypoxic events despite a higher incidence of desaturations overall. Similar to other studies, the need for airway intervention due to ventilation was minimal. We found a $1.4 \%$ incidence of BMV or placement of an airway (oropharyngeal and/or nasal), while Gouda et al. found a $1.2 \%$ incidence. ${ }^{6}$ None of the patients required intubation as a rescue technique during their endoscopic procedure and this was similar to other studies. ${ }^{6,8}$ Regardless of personnel or medications administered for endoscopies, the need for urgent airway management rescue was minimal.

Propofol doses were difficult to compare as studies differed in their form of administration, including bolus, infusion, and target controlled administration. ${ }^{9}$ Additionally, the efficiency and efficacy of the endoscopic procedure was difficult to compare as studies do not clearly define duration of the procedure. However, Hong et al. reported a mean time of colonoscopy procedure as $12 \mathrm{~min}$, while our average colonoscopy procedure time was $25 \mathrm{~min} .{ }^{11}$ In their study, all procedures were performed by one endoscopist, whereas there were different personnel from different specialties performing our endoscopies.

Goudra et al. reported the most commonly associated adverse events during EGD were cardiorespiratory events, including cardiac arrest, while bleeding was more frequent in colonoscopies. ${ }^{7}$ We did not have any of these complications. Additionally, they stated that the use of a core group of anesthesiologists for endoscopy may have facilitated reduction of adverse events with proactive approaches to airway management. ${ }^{7}$ Anesthesia-based teams may reduce the incidence of complications during simple endoscopies due to their preparedness in airway management and skill in administering medications. Therefore, patients with risk factors, such as obesity and hypoventilation syndromes, may benefit from ABT compared to endoscopists and RN only based teams. As the need for simple endoscopies increases, the demand of rural centers to perform them in patients with higher comorbidities may result in increased adverse events. Previous studies show that GI Suites have higher risk of adverse airway events than large academic centers. ${ }^{12}$ Similarly, the incidence of airway events in our rural hospital was higher other studies performed at tertiary care centers.

Our study had several limitations as it was a retrospective study in a small rural hospital in North Carolina. We did not include advanced or complex endoscopies, such as endoscopic retrograde cholangiopancreatography (ERCP). Also, it was difficult to determine the specific reasons for desaturations and/or need for airway intervention related to the doses of propofol.

\section{Conclusion}

In conclusion, we found that simple endoscopies performed by anesthesia-based teams may be performed in a safe and efficacious manner in a small, rural hospital. Our study may assist with the infrastructure for undergoing clinical research specific in rural hospitals and provide a model to other rural institutions. As the indications for endoscopies, aging population, and number of comorbidities increases, the need for more centers outside of large academic urban centers to perform safe, efficacious procedures will be paramount. Furthermore, our study finds that small rural hospitals may safely perform endoscopies without the need for patients to travel to larger tertiary hospitals. 


\section{Conflict of interest}

None declared by the authors.

\section{Authors' contribution}

All authors contributed equally to the conduct of the study and the preparation of the manuscript.

\section{References}

1. Repici A and Hassan C. The endoscopist, the anesthesiologists, and safety in $\mathrm{Gl}$ endoscopy. Gastrointestinal Endoscopy. 2017; 85(1): 109-111. [Free Full Text] DOI: 10.1016/i.gie.2016.06.025

2. Kudo $S$ and Kudo T. The necessity of colorectal cancer screening for elderly patients. Transl Gastroenterol Hepatol. 2017; 2:19. [PubMed] [Free Full Text] DOI: $10.21037 /$ tgh.2017.03.03

3. Rosow C. Improving safety during sedation by nonanesthesiologists: Do we lead or follow?. Anesth Analg. 2014; $119(1): \quad 7-8 . \quad$ [PubMed] DOI: $10.1213 / A N E .0000000000000277$

4. Early DS, Saifuddin T, Johnson JC, King PD, Marshall JB. Patient attitudes toward undergoing colonoscopy without sedation. Am J Gastroenterol. 1999; 94(7): 1862-5. DOI: 10.1111/j.1572-0241.1999.01219.x

5. Sonnenburg A. Sedation in colonoscopy. Gastroenterol Hepatol (N Y). 2016;12(5):327-329. [PubMed] [Free Full Text]

6. Gouda B, Gouda G, Borle A, Singh A, Sinha A, Singh PM. Safety of non-anesthesia provider administered propofol sedation in non-advanced gastrointestinal endoscopic procedures: A meta-analysis. Saudi J Gastroenterol. 2017;23(3):133-143. [PubMed] [Free Full Text] DOI: 10.4103/sjg.SJG_501_16

7. Goudra B, Nuzat A, Singh P, Borle A, Carlin A, Gouda $G$. Association between type of sedation and the adverse events associated with gastrointestianl endoscopy : an analysis of 5 years' data from a tertiary care center in the USA Clin Endosc. 2017;50(2):161-

169. [PubMed] [Free Full Text] DOI: $\underline{10.5946 / \text { ce.2016.019 }}$

8. Kulling D, Fantin A, Biro P, Bauerfeind P, Fried M. Safer colonoscopy with patient-controlled analgesia and sedation with propofol and alfentanil. Gastrointest Endosc. 2001:54:1-7. [PubMed] DOI: $10.1067 / \mathrm{mge} .2001 .116174$

9. Kulling D, Orlandi M, Inauen W. Propofol sedation during endoscopic procedures: how much staff and monitoring are necessary? Gastrointest Endosc. 2007;66(3):443-449.

[PubMed] DOI: $10.1016 /$ j.gie.2007.01.037

10. Basturk A, Artan R, Yilmaz A. Efficacy and safety of midazolam and ketamine in paediatric upper endoscopy. Arab J Gastroenterol. 2017;18(2):80-82. [PubMed] DOI: 10.1016/j.ajg.2017.05.004

11. Hong MJ, Sung I, Lee SP, Cheon B, Kang H, Kim T. Randomized comparison of recovery time after use of remifentanil alone versus midazolam and meperidine for colonoscopy anesthesia. Digestive Endoscopy. 2015; 27:113-120. [Free Full Text] DOI: $10.1111 /$ den. 12383

12. Goudra B, Singh PM. Providing Deep Sedation for Advanced Endoscopic Procedures: The Esthetics of Endoscopic Anesthetics. Dig Dis Sci. 2016;61:1426-8. [Free Full Text] DOI: 10.1007/s10620-016-4157-7 